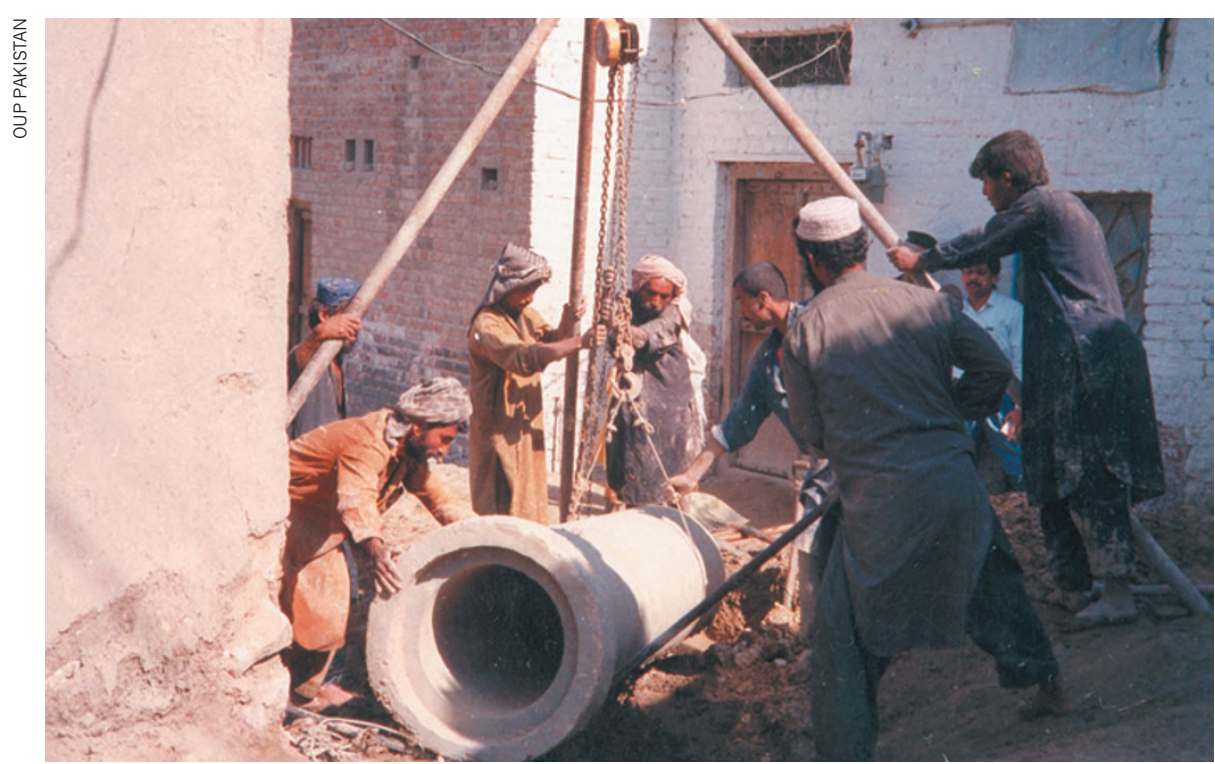

The underground sewage system that residents installed in Orangi has vastly improved public health.

Q\&A Arif Hasan

\title{
Architect of change
}

Urban campaigner and architect Arif Hasan has been central to a sanitary revolution, transforming Orangi, Karachi, from informal settlement to thriving community. Using his technical know-how, residents built a sewage system, sparking vast social change. Now chair of Pakistan's urbanization task force, he discusses incorporating sustainable design into poor cities.

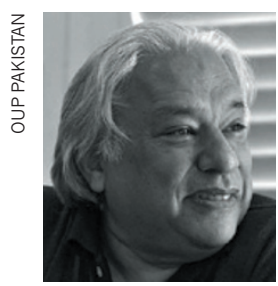

What challenges did Orangi face when you arrived?

In 1980, the lanes of Orangi, a katchi abadi or informal settlement housing a million people, were running with waste water and sewage, and infant mortality was 128 in 1,000 . The conditions stymied development: school attendance was down and trade difficult to establish. The psychological effects, too, were severe, sapping the will for change. The lanes couldn't be used as public space and quarrels over sanitation issues were frequent. The wastewater also damaged house foundations and triggered unhealthy rising damp.

\section{How did you become involved?}

That year, the social scientist Akhtar Hameed Khan set up the Orangi Pilot Project [OPP] to understand local problems and develop models to overcome the constraints governments face in upgrading informal settlements. Khan encouraged people to build and pay for their own underground sewage system, at a cost of around US\$30 a household. A year later, he needed an architect. That was me.

\section{How did you help?}

I proposed cheap, simple, local solutions: concrete-curing methods, casting cheap steel-shuttering manhole covers in situ, site-appropriate tools such as manual compactors, and surveys and maps. I also developed rules of thumb for gradients, manhole and pipe sizes, survey procedures and inexpensive one-chamber septic tanks. These designs and methods, which challenged conventional engineering standards, have stood the test of time. They also reduced costs by more than $40 \%$.

\section{How did sanitation transform public health?} By 2000 , some $85 \%$ of Orangi had self-laid, self-financed sewer lines. The lanes are clean: children play in them, women sit and talk. Health indicators have improved, and by 1993 infant mortality had fallen to 37 in 1,000 .

What are the social and economic changes? Literacy rates there are now among the highest in Pakistan. Socially and economically, Orangi is much more connected to the rest of Karachi in diverse ways. Many people are white-collar workers; a substantial minority are professionals; women and entrepreneurs work in and service formalsector industry.
Is Orangi a model for other cities?

As an outgrowth of the process of building sanitation communally, residents became community activists and got involved in OPPsupported health, education, housing and micro-credit programmes. The architects and technicians who helped to initiate the project now run it, and have expanded it to cities and settlements all over Pakistan, often in collaboration with local governments and planning agencies. The OPP's philosophy has had a major impact on the attitudes of professionals, academic institutions, government officials and international non-governmental organizations and agencies working in Pakistan.

What other urban problems are you tackling? In 1992, a square metre of land on the periphery of Karachi cost 1.7 times the daily wage. Today, it is 40 times. Many cannot afford that, so housing is getting denser. In the inner city, the density is more than 4,000 people per hectare [compared with less than 150 in London]. Although water supply and electricity provision have increased hugely in Karachi over the past 20 years, the sharing of toilets and kitchens has risen, along with the number of people per room. You can't live a comfortable life at such densities unless they are planned for.

\section{What are your solutions?}

With colleagues, I have developed design guidelines and incremental development processes to accommodate high densities in an environmentally friendly, affordable way. We hypothetically redesigned four different Karachi communities with computer modelling. Three redesigns showed that densities even higher than those prescribed by the Karachi Building Control Authority were workable.

What other challenges does Karachi face? Many natural drainage channels and water bodies have been filled in to make way for elite coastal housing and new informal settlements upstream. So all of Karachi now floods. But other environmental issues are arising because of the new paradigm of Karachi as a 'world-class city', fuelled by direct foreign investment. New infrastructure caters to the corporate sector, and its architectural style imitates the West. There is a new dependence on air conditioning despite local expertise in creating buildings comfortable without it.

\section{How has architecture in Karachi changed?} When I began my practice in 1968, an architect designed for the state, or for the rich. Today, clients vary hugely. This new architectural world belongs to women, who make up $92 \%$ of the architecture and planning students at the University of Karachi. In many ways, the role of the architect is immense compared to before.

INTERVIEW BY ANNA PETHERICK 